\title{
Yenidoğan Yoğun Bakım Hemşireliği: Yenidoğan Bakımına İlişkin Rol ve Bakım Kriterleri Farkındalığı
}

\author{
Emine Yarar ${ }^{1} \oplus$, Sibel Küçü̈²
}

'Bağımsız, Hemşirelik, Aksaray, Türkiye

${ }^{2}$ Ankara Yıldırım Beyazıt Üniversitesi Sağlık Bilimleri Fakültesi, Hemşirelik Bölümü Çocuk Sağlığı ve Hastalıkları Hemşireliği , Ankara, Türkiye

Emine Yarar, Uzm. Hemşire Sibel Küçük, Doç. Dr.

İletişim:

Uzm. Hemşire Emine Yarar

Bağımsız, Hemşirelik, Aksaray, Türkiye

Tel: +905413710130

E-Posta: emineyarar1968.ey@gmail.com

Gönderilme Tarihi : 28 Temmuz 2018

Revizyon Tarihi ：09 Ekim 2018

Kabul Tarihi : : 07 Aralık 2018
ÖZET

Amaç: Araştırma yenidoğan yoğun bakım ünitesi hemşirelerinin yenidoğan bakımına ilişkin rolleri ve bakım kriterlerine yönelik farkındalıklarının belirlenmesi amacıyla yapılmıştır.

Gereç ve Yöntem: Araştırma 116 YYBÜ hemşiresi ile tanımlayıcı olarak yapıImıştır. Veriler 33 sorudan oluşan anket formu ile toplanmıştır. Verilerin değerlendirilmesinde sayı, yüzde, ki kare testleri kullanılııștır. Anlamlııı düzeyi $p<0,05$ olarak kabul edilmiştir.

Bulgular: Hemşirelerin diğer sağlık disiplinleri birlikte karar verip gerçekleştiren rollere karar vermede fototerapi gereksinimini, yara bakımını, yenidoğanın oral beslenmeye başlamasını konularında doğru yanıt oranları yüksektir. Bağımsız olarak karar verilip gerçekleştirilen rollere ise en fazla alt/pişik bakımı, yenidoğan-aile iletişimi konularında doğru yanıt vermiştir. Öğrenim durumu ile ventilatör desteği alan yenidoğan bakımı, ağı yönetimi ve termoregülasyon düzenlemesi, oral beslenmeye başlama kriterleri arasında istatistiksel anlamlı fark vardır $(p<0,05)$. Meslekte çalışma yılı ile yenidoğanın alt/pişik bakımı, yenidoğan yoğun bakım ünitesinde çalışma yılı ve haftalık çalışma saati ile yara bakımı kriterlerini bilme durumu arasında anlamlı fark bulunmaktadır $(p<0,05)$.

Sonuç: Hemşirelerin bağımsız olarak karar verilip gerçekleştirilen ve diğer sağlık disiplinleri birlikte karar verip gerçekleştiren rolleri kesin bir ayrım yapamadıkları belirlenmiştir. Hemşirelik rollerinin farkına varılması ve uygulamada etkin kullanılabilmesi amacıyla eğitim programları ile hemşirelerin farkındalıklarının arttırııması önerilebilir.

Anahtar sözcükler: Bakım, hemşire, rol, yenidoğan, yoğun bakım

\section{NEWBORN/NEONATAL INTENSIVE CARE NURSING: AWARENESS OF THE ROLES AND CARE CRITERIA FOR NEONATAL/ NEONATAL CARE}

\section{ABSTRACT}

Purpose: The study was conducted to determine the awareness of newborn/neonatal intensive care unit nurses about roles and care criteria in relation to newborn/neonatal care.

Materials and Methods: The study was conducted with 116 NICU nurses, as descriptive. Data were collected using a questionnaire form that included 33 questions. For data evaluation, frequency, percentage, chi-square tests were used. The significance level was accepted as $p<0.05$.

Results: True answer levels about phototherapy need, wound care, starting oral feeding as roles that are decided with other health disciplines were high. Again, the most true/truest answer was given for independent roles such as diaper rash care, newborn-family communication. There was a significant difference between education level with newborn who took ventilator support, pain management, thermoregulation setting, starting oral feeding $(p<0.05)$. Also, there was a significant difference between the working year and diaper rash care, working time at the intensive care unit and wound care and knowing wound care criteria $(\mathrm{p}<0.05)$.

Conclusion: It is determined that nurses could not do any certain analysis between roles that are decided as independent together with other health disciplines. It is suggested that awareness of nurses about this issue should be increased by education programsin order to realize nursing roles and to use them effectively in practice.

Keywords: Care, intensive care, newborn, nurse, role 
$\mathbf{H}$ emşirelik bakımı fiziksel, psikolojik ve sosyal yönden mevcut ya da olası sağlık problemlerine sahip bireyin bakım gereksinimlerini belirleme, karar verme, uygulama, değerlendirme ve kendi gereksinimlerini karşılayabilir düzeye getirmeye yönelik yardım edici ve savunucu bir ilişkidir. Hemşirelik bakımı aynı zamanda hemşirelik mesleğinin etik ve yasal bir sorumluluğudur (1). Bireyler her geçen gün daha çok hemşirelik bakımına ihtiyaç duymakta ve hemşirelik bakımının değişkenliği de önemli derecede artmaktadır (2).

Hemşirelik kuramsal bilgi ve beceriyi içeren, uygulamalı bir sağlık disiplini olması nedeniyle eğitim, uygulama, görev tanımları, meslek işlevleri ve rolleri açısından sürekli olarak gelişmekte ve değişmektedir. Bu değişiklikler içerisinde değişmeyen tek gerçek, hemşireliğin bireylere bakım verme sürecini devam ettirmesidir (1). Hemşirelik bakım uygulamalarının önemsenmesi hemşireliğin gelişimi ve niteliği açısından da önemlidir (3). Sağlıklı/hasta bireyin ve ailesinin gereksinimlerini karşılama ve en kısa zamanda onları bağımsız hale getirerek yaşam kalitelerini arttırmayı amaçlayan hemşirelik, günümüzde hala sadece hekimin planladığı tedaviyi uygulayan, yardım eden ve destekleyen meslek grubu olarak görülmektedir. Oysaki bu durum gerçeği yansıtmamaktadır (1). Hemşirelik, hekim istemine göre gerçekleştirilen roller, diğer sağlık disiplinleri birlikte karar verip gerçekleştiren roller ve bağımsız olarak karar verilip gerçekleştirilen rolleri ile önemli bir konumda yer almaktadır. Hekim istemine göre gerçekleştirilen roller hekim direktifini uygulama, tanı ve tedavi işlemlerine yardım etmeyi içerirken, diğer sağlık disiplinleri birlikte karar verip gerçekleştiren roller ve bağımsız olarak karar verilip gerçekleştirilen roller aşamalı olarak direktiften insiyatif kullanmaya doğru değişmekte ve mesleğe özgü bilgi, becerileri ve deneyimleri uygulamaya olanak vererek mesleksel otonomiyi desteklemektedir. Bu nedenle hemşireliği kendine özgü bir meslek haline getiren önemli bir unsur bağımsız olarak karar verilip gerçekleştirilen rolleridir. Bağımsız olarak karar verilip gerçekleştirilen roller; bilgi ve deneyimler kullanılarak sağlığını sürdürmesi, yükseltilmesi, sağlığını yeniden kazanması ve taburculuk sonrası en üst düzeyde yaşam kalitesine ulaşılabilmesi için kullanılmaktadır (4).

Hemşirelerin bakım uygulamaları için ayırdıkları zaman oranlarının kliniklere göre farklılık gösterdiği bilinmektedir (5). YYBÜ'lerinde (YYBÜ) hemşirelerin yenidoğanın doğrudan bakım uygulamalarına zaman ayırma oranlarının \%37-53 arasında olduğu bildirilmektedir $(6,7)$. Hemşireliğin bağımsız olarak karar verdiği rollerinde artış sağlanması, mesleğin bilimsel bilgi birikiminin ve uygulama olanaklarının yanı sıra hemşirelerin yetkilerinin artmasına, otonomilerinin sağlamlaşmasına katkıda bulunabilecektir. Diğer sağlık disiplinleri birlikte karar verip gerçekleştiren roller ve bağımsız olarak karar verilip gerçekleştirilen rolleri sayısının arttırılması hemşireliğin gelecekte daha etkili ve verimli bir meslek olması ve hastalara verilen bakımın verimliliği-işlevselliği açısından önemlidir. YYBÜ hemşirelerinin bu rollerinin farkına varmaları ve rolleri etkin bir şekilde üstlenmelerine olanak sağlayarak gerek mesleksel yetilerinin ve otonomilerinin, gerekse hasta bakımının kalitesinin ve iş doyumlarının artmasına yardımcı olabilecektir (8).

\section{Gereç ve yöntem}

\section{Araştırmanın amacı ve tipi}

Araştırma yenidoğan yoğun bakım ünitesi hemşirelerinin yenidoğan bakımına ilişkin rolleri ve bakım kriterlerine yönelik farkındalıklarının belirlenmesi amacıyla tanımlayıcı olarak yapılmıştır.

\section{Evren ve örneklem}

Araştırmanın evrenini Ankara il merkezinde hizmet veren 3 kadın doğum ve çocuk hastanesinde çalışan 165 hemşire oluşturmuştur. Herhangi bir örneklem seçimine gidilmemiştir. En az 6 aydır YYBÜ hemşiresi olan ve araştırmaya katılmayı gönüllü kabul eden 116 hemşire araştırmanın örneklemini oluşturmuştur.

\section{Verilerin toplanması}

Verilerin toplanması 25,12,2015-25,06,2016 tarihleri arasında araştırmacılar tarafından oluşturulan veri toplama formu ile toplanmıştır. Veri toplama formu sosyo demografik özellikleri sorgulayan 8 ve literatür doğrultusunda (1,9-11) oluşturulan hekim direktifi hemşire kararı ve sadece hemşire kararı ile yapılan bakım uygulamalarını sorgulayan 25 olmak üzere toplam 33 sorudan oluşmaktadır.

Veriler araştırmacılar tarafından yüzyüze görüşme yöntemi ile toplanmıştır.

Verilerin değerlendirilmesinde sayı, yüzde, ki kare testleri kullanılmıştır. Anlamlılık düzeyi $\mathrm{p}<0,05$ olarak kabul edilmiştir (IBM SPSS Statistics 21,0 (IBM Corp. Released 2012. IBM SPSS Statistics for Windows Version 21,0. Amornk, NY: IBM Corp.).

\section{Araştırmanın etik boyutu}

Araştırmaya başlanmadan önce gerekli etik (AYBÜ, $(03,09,2015 / 08)$ ve yasal izinler (Dr. Sami Ulus Kadın Doğum Çocuk Sağlığı ve Hastalıkları EAH, 07,04,2016/73799008, 
Etlik Zübeyde Hanım Kadın Hastalıkları EAH, 03,03,2016/90057707-900, Ankara Çocuk Sağlığı ve Hastalıkları Hematoloji Onkoloji EAH, 24,12,2015/07870) alınmıştır. Hemşirelerden gönüllü araştırma onam formu ile onam alınmıştır.

\section{Bulgular}

YYBÜ hemşirelerinin \%85,3'ünün 21-35 yaşlarında, \%88,8'inin kadın ve \%75,0'ının lisans/yüksek lisans düzeyinde eğitime sahip olduğu belirlenmiştir. Hemşirelerin \%45,7'si 6-10 yıldır hemşire, \%61,2'si 1-5 yıldır YYBÜ hemşiresi olarak, \%60,3'ü haftada 41 saat ve üzerinde çalıştığı saptanmıştır (Tablo 1).

Hekim direktifi ve hemşire kararı ile uygulanması gereken rollerden oral beslenmeye başlanmasını hemşirelerin $\% 91,4$ 'ü, yara bakımını \%92,2'si, fototerapi gereksinimini \%98,3'ü, IV ilaç uygulamasına bağlı semptom oluşumunda izlenecek prosedürü \%85,3'ü doğru bilmektedir. Yalnızca hemşire kararı ile uygulanan rollerden standart bir yenidoğan için alt/pişik bakımını hemşirelerin $\% 64,7$ 'sinin, yenidoğan-aile iletişiminin sağlamasını $\% 53,4$ 'ünün, termogülasyon düzenlemesini \%31'inin doğru bildiği saptanmıştır (Tablo 2).

Hemşirelerin \%67,2'si yenidoğanın oral beslenmeye başlaması, $\% 51,7^{\prime} i$ umblikal kateter, $\% 27,5^{\prime}$ i yara bakımı, \%27,5'i ventilatör desteği alan yenidoğan bakımı, $\% 21,5^{\prime} \mathrm{i}$ ağrı yönetimi, $\% 69,8$ 'i aspirasyon gereksinimi, $\% 58,6$ 'sı fototerapi gereksinimi, \%40,5'i IV ilaç uygulamasına bağlı semptom oluşumunda izlenilecek prosedür, $\% 54,3$ 'ü geçici takipne klinik bulgularını yenidoğan bakımı uygulamalarına göre diğer sağlık disiplinleri birlikte karar verip gerçekleştiren rollerine karar verme kriterleri doğru bilmektedir. Yine hemşirelerin \%24,1'i standart bir yenidoğan için alt/pişik bakımı, \%67,2'si yenidoğan-aile iletişimi, \%37,0'si termogülasyon düzenlemesi, \%37,0'si banyo sıklığı, \%21,5'i ağız bakımını yenidoğan bakımı uygulamalarına göre bağımsız olarak karar verilip gerçekleştirilen rollerine ilişkin karar verme kriterleri doğru bildiği saptanmıştır (Tablo 3).

Yenidoğan bakımına ilişkin rollerden oral beslenme ile öğrenim durumu arasında, alt/pişik bakımı ile meslekte çalışma yılı 6-10 yıl olan, yara bakımı ile haftalık 40 saat çalışma, ventilatör desteği alan yenidoğan bakımı ile öğrenim durumu arasında anlamlı fark belirlenmiştir. Ağrı yönetimi ile yaş ve öğrenim durumu arasında (sırasıyla $p=0,02, p=0,03)$, fototerapi gereksinimi ile çocuk sahibi olma durumu arasında anlamlı bir fark vardır $(p<0,05)$ (Tablo 4).
Tablo 1. Hemşirelerin sosyodemografik özellikleri

\begin{tabular}{lcc} 
Değişkenler ( $\boldsymbol{n = 1 1 6 )}$ & $\boldsymbol{n}$ & $\%$ \\
\hline Yaş & 99 & 85,3 \\
21-35 Yaş & 27 & 14,7 \\
36 Yaş ve Üstü & 103 & 88,8 \\
\hline Cinsiyet & 13 & 11,2 \\
Kadın & & \\
Erkek & 29 & 25,0 \\
\hline Eğitim durumu & 87 & 75,0 \\
Lise-Ön Lisans & 35 & 30,2 \\
Lisans-Yüksek Lisans & 53 & 45,7 \\
\hline Meslekte çalışma yılı & 28 & 24,1 \\
1-5 Yıl & & \\
6-10 Yıl & 71 & 61,2 \\
11 Yıl ve Üstü & 35 & 30,2 \\
\hline YYBÜ'de çalışma yılı & 10 & 8,6 \\
1-5 Yıl & 46 & 39,7 \\
6-10 Yıl & 70,3 \\
11 Yıl ve Üstü & & \\
\hline Haftalık çalışma saati & & \\
40 Saat & & \\
41 Saat ve Üstü & & \\
\hline
\end{tabular}

Tablo 2. Rollere göre bakım uygulama kriterlerine karar verme durumu $(n=116)$

Uygulamaya karar verme

\begin{tabular}{cccc}
\hline Rol* & $\begin{array}{c}\text { Hekim direktifi } \\
\text { ve hemşire } \\
\text { kararı }\end{array}$ & $\begin{array}{c}\text { Yalnızca } \\
\text { hemşire } \\
\text { kararı }\end{array}$ \\
\hline & $n$ & $\%$ & $n$
\end{tabular}

Hekim direktifi ve hemşire kararı ile uygulanması gereken roller Oral beslenmeye bașlanması

$\begin{array}{lllll}\text { Umlikal kateter bakımı } & 87 & 75,0 & 29 & 25,0\end{array}$

$106 \quad 91,4 \quad 10 \quad 8,6$

$\begin{array}{lllll}\text { Yara bakımı } & 107 & 92,2 & 9 & 7,8\end{array}$

Ventilatör desteği alan yenidoğan bakımı $\quad 86 \quad 74,1 \quad 30 \quad 25,9$

Ağrı yönetimi

$82 \quad 70,7 \quad 34 \quad 29,3$

Aspirasyon gereksinimi

$65 \quad 56,0 \quad 51 \quad 44,0$

Fototerapi gereksinimi

$\begin{array}{llll}114 & 98,3 & 2 & 1,7\end{array}$

IV İlaç uygulamasına bağlı semptom

$99 \quad 85,3 \quad 17 \quad 14,7$ oluşumunda izlenilecek prosedür

\begin{tabular}{llllll}
\hline $\begin{array}{l}\text { Yalnızca hemşire kararı ile uygulanması } \\
\text { gereken roller }\end{array}$ & & & & \\
Alt/pişik bakımı & 41 & 35,3 & 75 & 64,7 \\
Yenidoğan-aile iletişiminin sağlanması & 54 & 46,6 & 62 & 53,4 \\
Termogülasyon düzenlemesi & 80 & 69,0 & 36 & 31,0
\end{tabular}

*Soruya birden fazla yanıt verilmiștir. Yüzdeler $n$ sayıları üzerinden hesaplanmıștı. 
Tablo 3. Rollere göre bakım uygulamalarına karar verme kriterlerini bilme durumu $(n=116)$

\begin{tabular}{lcccc} 
Rol* & \multicolumn{2}{c}{ Bilen } & \multicolumn{2}{c}{ Bilmeyen } \\
\hline & $\boldsymbol{n}$ & $\%$ & $\boldsymbol{n}$ & $\%$ \\
\hline Hekim direktifi ve hemşire kararı ile & & & & \\
uygulanması gereken roller & & & & \\
Oral beslenmeye başlanması & 78 & 67,2 & 38 & 32,7 \\
Umlikal kateter bakımı & 60 & 51,7 & 56 & 48,2 \\
Yara bakımı & 32 & 27,5 & 84 & 72,4 \\
Ventilatör desteği alan yenidoğan bakımı & 32 & 27,5 & 84 & 72,4 \\
Ağrı yönetimi & 25 & 21,5 & 91 & 78,4 \\
Aspirasyon gereksinimi & 81 & 69,8 & 35 & 30,1 \\
Fototerapi gereksinimi & 68 & 58,6 & 48 & 41,3 \\
IV Illaç uygulamasına bağlı semptom & 47 & 40,5 & 69 & 59,4 \\
Oluşumunda izlenilecek prosedür & & & & \\
\hline Yalnızca hemşire kararı ile uygulanması & & & & \\
gereken roller & & & & \\
Alt/pişik bakımı & 28 & 24,1 & 88 & 75,8 \\
Yenidoğan-aile iletişimi & 78 & 67,2 & 38 & 32,7 \\
Termogülasyon düzenlemesi & 43 & 37,0 & 73 & 62,9 \\
\hline
\end{tabular}

*Soruya birden fazla cevap verilmiştir. Yüzdeler $\mathrm{n}$ sayılları üzerinden hesaplanmıştır.

\section{Tartışma}

Literatürde oral beslenmeye başlanma, umblikal katater, yara ve ventilatör desteği alan yenidoğan bakımı, ağrı yönetimi, aspirasyon ve fototerapi gereksinimi, IV ilaç uygulamasına bağlı semptom oluşumunda izlenilecek prosedürün hemşirelerin hekim direktifi ve hemşire kararı ile uygulaması gereken hemşirelik rollerinden olduğu bildirilmektedir (1,9-11). Bu çalışmada YYBÜ hemşirelerinin aspirasyon gereksinimine karar verme hariç diğer hekim direktifi ve hemşire kararı ile uygulanan rollerini bilme oranının yüksek olduğu saptanmıştır (Tablo 2). Ancak hekim direktifi ve hemşire kararı ile uygulanan rollere karar verme kriterlerini hemşirelerin bilme oranları düşüktür (Tablo 3). Oral beslemeye başlama kararını hemşirelerin 1/4'ünün kendi kararları ile uygulayacaklarını bildirmeleri dikkat çekidir (Tablo 2). Benzer şekilde Tengir (2008) hemşirelerin yenidoğan beslenmesi konusunda bilgi ve uygulamalarda eksiklikleri olduğunu bildirmektedir (12). Eğitim düzeyi arttıkça, özellikle lisans ve üzeri öğrenim

Tablo 4. Hemşirelerin sosyodemografik özellikleri ile rollere göre bakım uygulama kriterlerini bilme durumunun karşılaştırıması

\begin{tabular}{|c|c|c|c|c|c|c|c|c|c|c|c|c|c|c|c|c|c|c|c|c|}
\hline \multirow[t]{3}{*}{ Özellikler } & \multicolumn{4}{|c|}{$\begin{array}{c}\text { Oral beslenmeye } \\
\text { başlama }\end{array}$} & \multicolumn{4}{|c|}{ Alt/pişik bakımı } & \multicolumn{4}{|c|}{ Yara bakımı } & \multicolumn{4}{|c|}{$\begin{array}{c}\text { Ventilatör desteği alan } \\
\text { yenidoğan bakımı }\end{array}$} & \multicolumn{4}{|c|}{ Ağrı yönetimi } \\
\hline & \multicolumn{2}{|c|}{ Bilen } & \multicolumn{2}{|c|}{ Bilmeyen } & \multicolumn{2}{|c|}{ Bilen } & \multicolumn{2}{|c|}{ Bilmeyen } & \multicolumn{2}{|c|}{ Bilen } & \multicolumn{2}{|c|}{ Bilmeyen } & \multicolumn{2}{|c|}{ Bilen } & \multicolumn{2}{|c|}{ Bilmeyen } & \multicolumn{2}{|c|}{ Bilen } & \multicolumn{2}{|c|}{ Bilmeyen } \\
\hline & $n$ & $\%$ & $n$ & $\%$ & $n$ & $\%$ & $n$ & $\%$ & $n$ & $\%$ & $n$ & $\%$ & $n$ & $\%$ & $n$ & $\%$ & $n$ & $\%$ & $n$ & $\%$ \\
\hline \multicolumn{21}{|l|}{ Yaş } \\
\hline $21-35$ & 67 & 67,7 & 32 & 32,3 & 27 & 27,3 & 72 & 72,7 & 28 & 28,3 & 71 & 71,7 & 31 & 31,3 & 68 & 68,7 & 25 & 25,3 & 74 & 74,7 \\
\hline 36 ve Üstü & 11 & 64,7 & 6 & 35,3 & 1 & 5,9 & 16 & 94,1 & 4 & 23,5 & 13 & 76,5 & 1 & 5,9 & 16 & 94,1 & 0 & 0,0 & 17 & 100,0 \\
\hline Analiz & \multicolumn{4}{|c|}{$X 2=0,05 ; p=0,78$} & \multicolumn{4}{|c|}{$X 2=3,62 ; p=0,06$} & \multicolumn{4}{|c|}{$X 2=0,16 ; p=0,77$} & \multicolumn{4}{|c|}{$X 2=4,69 ; p=0,03$} & \multicolumn{4}{|c|}{$X 2=5,47 ; p=0,02$} \\
\hline \multicolumn{21}{|l|}{ Cinsiyet } \\
\hline Kadın & 72 & 69,9 & 31 & 30,1 & 25 & 24,3 & 78 & 75,7 & 29 & 28,2 & 74 & 71,8 & 26 & 25,2 & 77 & 74,8 & 21 & 20,4 & 82 & 79,6 \\
\hline Erkek & 6 & 46,2 & 7 & 53,8 & 3 & 23,1 & 10 & 76,9 & 3 & 23,1 & 10 & 76,9 & 6 & 46,2 & 7 & 53,8 & 4 & 30,8 & 9 & 69,2 \\
\hline Analiz & \multicolumn{4}{|c|}{$X 2: 2.95 ; p: 0.11$} & & $2: 0.09$ & $p: 1$ & & & $2: 0.14$ & p:1. & & & $2: 2.52$ & $\mathrm{p}: 0$ & & & $2: 0.73$ & $\mathrm{p}: 0.4$ & \\
\hline Öğrenim Durumu & & & & & & & & & & & & & & & & & & & & \\
\hline Lise-Ön Lisans & 14 & 48,3 & 15 & 51,7 & 4 & 13,1 & 25 & 86,2 & 9 & 31,0 & 20 & 69,0 & 3 & 10,3 & 26 & 89,7 & 2 & 6,9 & 27 & 93,1 \\
\hline Lisans-Yüksek Lisans & 64 & 73,6 & 23 & 26,4 & 24 & 27,6 & 63 & 72,4 & 23 & 26,4 & 64 & 73,6 & 29 & 33,3 & 58 & 66,7 & 23 & 26,4 & 64 & 73,6 \\
\hline Analiz & & $=6,31$ & $p=0$ & & & $=2,26$ & $p=0$ & & & $=0,23$ & $p=c$ & & & $=5,75$ & $p=0$ & & & $=4,91$ & $p=0$ & 03 \\
\hline Meslekte Çalışma Yılı & & & & & & & & & & & & & & & & & & & & \\
\hline $1-5 Y_{I}$ & 25 & 71,4 & 10 & 28,6 & 10 & 28,6 & 25 & 71,4 & 9 & 25,7 & 26 & 74,3 & 12 & 34,3 & 23 & 65,7 & 10 & 28,6 & 25 & 71,4 \\
\hline $6-10$ YII & 33 & 62,3 & 20 & 37,7 & 16 & 30,2 & 37 & 69,8 & 12 & 22,6 & 41 & 77,4 & 16 & 30,2 & 37 & 69,8 & 12 & 22,6 & 41 & 77,4 \\
\hline 11 Yıl ve Üstü & 20 & 71,4 & 8 & 28,6 & 2 & 7,2 & 26 & 92,8 & 11 & 39,3 & 17 & 60,7 & 4 & 14,3 & 24 & 85,7 & 3 & 10,7 & 25 & 89,3 \\
\hline Analiz & & $=1,09$ & $p=0$ & & & $=5,85$ & $p=0$ & & & $=2,62$ & $p=c$ & & & $=3,44$ & $p=0$ & & & $=3,00$ & $p=0$ & 22 \\
\hline $\begin{array}{l}\text { Yoğun Bakım Ünitesinde } \\
\text { Çalışma Yılı }\end{array}$ & & & & & & & & & & & & & & & & & & & & \\
\hline $1-5$ YIl & 46 & 64,8 & 25 & 35,2 & 17 & 23,9 & 54 & 76,1 & 14 & 19,7 & 57 & 80,3 & 21 & 29,6 & 50 & 70,4 & 12 & 16,9 & 59 & 83,1 \\
\hline $6-10$ YII & 22 & 62,9 & 13 & 37,1 & 9 & 25,7 & 26 & 74,3 & 13 & 37,1 & 22 & 62,9 & 9 & 25,7 & 26 & 74,3 & 11 & 31,4 & 24 & 68,6 \\
\hline 11 Yıl ve Üstü & 10 & 10,0 & 0 & 0,0 & 2 & 20,0 & 8 & 80,0 & 5 & 50,0 & 5 & 50,0 & 2 & 20,0 & 8 & 80,0 & 2 & 20,0 & 8 & 80,0 \\
\hline Analiz & & $2: 5,37$ & $\mathrm{p}: 0$, & & & $2=0,1$ & $4 ; p: 0$ & & & $2: 6,31$ & $\mathrm{p}: 0$, & & & $=0,49$ & $p=0$ & & & $=2,94$ & $p=0$ & \\
\hline Haftalık Çalışma Saati & & & & & & & & & & & & & & & & & & & & \\
\hline 40 Saat & 30 & 65,2 & 16 & 34,8 & 11 & 23,9 & 35 & 76,1 & 19 & 41,3 & 27 & 58,7 & 14 & 30,4 & 32 & 69,6 & 12 & 26,1 & 34 & 73,9 \\
\hline 41 Saat ve Üstü & 48 & 68,6 & 22 & 31,4 & 17 & 24,3 & 53 & 75,7 & 13 & 18,6 & 57 & 81,4 & 18 & 25,7 & 52 & 74,3 & 13 & 18,6 & 57 & 81,4 \\
\hline Analiz & & $=0,14$ & $p=0$ & & & $=0,02$ & $p=1$ & & & $=7,18$ & $p=0$ & & & $=0,31$ & $p=0$ & & & $=0,92$ & $p=$ & \\
\hline
\end{tabular}


düzeyine sahip hemşirelerin oral beslemeye başlamanın diğer sağlık disiplinleri birlikte karar verip gerçekleştiren rollerinden olduğunu ve çalışma yılının artması yara bakımı kriterlerini bilme oranları artmaktadır. Eğitim düzeyi ve yoğun bakımda çalışma süresi yara bakımı kriterlerini bilmede anlamlı fark oluşturmaktadır $(p<0,05)$

YYBÜ'de sıklıkla uygulanan aspirasyon uygulamasını hemşirelerin yarıya yakını kendi kararları ile uygulayacakları roller arasında görmekte ve aspirasyon uygulaması karar verme kriterlerini 1/3'ü bilmemektedir (Tablo2, 3). Bu çalışmayla benzer şekilde Selalmaz ve arkadaşları (2015) hemşirelerin fototerapi uygulaması konusunda yeterince bilgi sahibi olmadıklarını bildirmektedir (13). Hemşirelerin sosyodemografik ve mesleksel özellikleri aspirasyon uygulama kriterlerini bilmede anlamlı bir fark oluşturmamaktadır ( $p>0,05)$ (Tablo 4).

Bu araştırmada ventilatör desteği alan yenidoğan bakımını hemşirelerin 1/3'üne yakını kendi kararları ile uygulayabileceklerini yapabileceklerini belirtmiştir (Tablo 2). YYBÜ'de ventilatörle solunum desteği gereksinimi olan yenidoğanların bakımının özel bilgi birikimi gerektirdiği ve yenidoğanla sürekli temas halinde olan ve gözlem yapan hemşirelerin bilgi düzeylerinin önemli olduğu bildirilmesine karşın $(14,15)$ hemşirelerin \%72'si uygulamaya karar verme kriterini bilmemektedir (Tablo 3). 21-35 yaş arasında genç olan hemşirelerin doğru yanıt verme oranlarının arttığı, yaş ile ventilatör desteği alan yenidoğan bakımına verilen doğru yanıtlar arasında istatistiksel olarak anlamlı fark olduğu saptanmıştır $(p<0,05)$ (Tablo 4). Özellikle eğitim seviyesinin yükselmesi konu hakkındaki doğru yanıtları arttırmaktadır. Eğitim düzeyi arttıkça özellikle lisans ve üzerinde eğitime sahip olan hemşireler daha yüksek oranda ventilatör desteği alan yenidoğan bakımı ile ilgili doğru yanıt vermiştir ve öğrenim düzeyi ve bakım arasında anlamlı bir fark vardır $(p<0,05)$.

Hemşirelerin büyük çoğunluğu IV İlaç uygulamasına bağI semptom oluşumunda izlenilecek prosedürün hekim direktifi ve hemşire kararı ile uygulanması gereken rollerinden olduğunu bilmektedir (Tablo 2). Ancak Gomes ve arkadaşları (2011) çalışmalarına (16) benzer şekilde hemşirelerin komplikasyon bulguları saptandığında gerekli müdahaleler hakkında yeterli bilgi sahibi olmadıkları tespit edilmiştir (Tablo 3). Hemşirelerin sosyodemografik ve mesleksel özellikleri ise IV İlaç uygulamasına bağlı semptom oluşumunda izlenilecek prosedürde anlamlı bir fark oluşturmamaktadır ( $p>0,05)$ (Tablo 4). Hemşirelerin IV ilaç uygulamasına bağlı oluşabilecek semptomlarla karşılaşıdığında izlenilmesi gereken prosedürleri bilmediği ancak bu semptom yönetiminin hangi hemşirelik rolleri içerisinde yer aldığını bildikleri görülmektedir.

Hemşireler fototerapi tedavisinin diğer sağlık disiplinleri birlikte karar verip gerçekleştiren ve bağımsız olarak karar verilip gerçekleştirdiği rolleri olduğu konusunda bir ayrım yapabilmekte ancak yenidoğanda fototerapi gereksinimi kriterlerini eksik bilmekte ve çocuk sahibi olma ile fototerapi gereksinimine karar verme kritelerini bilme arasında anlamlı fark bulunmaktadır $(p<0,05)($ Tablo 3,4$)$.

Yenidoğanın sağlığının sürdürülmesinde cilt bakım uygulamalarının önemli olduğu ve yenidoğan cilt hasarları yönünden koruması gerektiği bildirilmektedir (17). Hemşireler genellikle rutin olarak uyguladıkları bakımın yara bakımına yönelik olduğunu ve hekim istemi hemşire kararıyla uygulayabileceklerini bilmekte ancak yara bakımı uygulama kriterlerini tam olarak bilmemektedir (Tablo 2, 3). YYBÜ'de ve haftalık çalışma süresi arttıkça hemşirelerin daha fazla oranda yara bakımı kriterleri ile ilgili doğru yanıt verdikleri ve haftalık çalışma süresi ile yara bakımı kriterlerini bilme arasında anlamlı fark oluştuğu saptanmıştır $(p=0,05)$ (Tablo 4).

Yenidoğanda ağrı yönetimine karar vermenin hemşirenin hekim direktifi ve kendi kararı ile uygulanması gereken rollerinden olduğunu bilme oranları yüksektir. Ancak hemşirelerin azımsanmayacak bir bölümü ağrı yönetiminin kendi kararları uygulayacağı rollerden olduğunu bildirmesine karşın uygulamaya karar verme kriterlerini bilmemektedir (Tablo 2,3). Hemşirelerin ağrı yönetimini kendi kararları ile uygulayacakları rolleri arasında görmelerinin ağrıyı gidermede nonfarmakolojik yöntem kullanılma oranlarının yüksek $(18)$ ve etkili olması $(19,20)$ ile ilişkili olabileceği düşünülmüştür. Yaşın ve öğrenim düzeyinin yükselmesi ağrı yönetimine karar verme kriterlerini bilmeyi etkilemekte ve anlamlı fark oluşturmaktadır $(p<0,05)$ (Tablo 4). Hemşirelerin çoğunluğunun ağrı yönetimine karar verme kriterlerini bilmemelerinin hemşirelerin rol karmaşası yaşamalarına ve ağrı yönetiminde tamamen hekime bağımlı hale gelmelerine neden olabileceği düşünülmüştür.

Yenidoğanın umblikal katater uygulamalarının NEC dahil olmak üzere pek çok komplikasyona neden olabildiği bildirilmektedir $(21,22)$. Hemşirelerin \%25'i umblikal katater bakımını kendi kararları ile uygulayacakları rollerden olduğunu bildirmekte (Tablo 2) ancak yarıya yakını uygulama kriterlerini bilmektedir (Tablo 3). Umblikal katater bakımı hemşirelerin rutin uyguladıkları bakımlardan biri olmasına karşın bakıma karar verme kriterleri tam olarak bilinmemektedir. 
Literatürde yenidoğanda alt/pişik bakımı, yenidoğan-aile iletişiminin sağlanması ve termogülasyon düzenlemesinin hemşirelerin yalnızca kendi kararları ile uygulayacakları rolleri arasında olduğu bildirilmesine $(1,9-11)$ karşın hemşirelerin azımsanmayacak bir bölümü alt/pişik bakımı, yenidoğan aile iletişiminin sağlanması ve özellikle de termoregülasyonun düzenlenmesi uygulamalarının hekim direktifi ve kendi kararları ile uygulanması gerektiğini belirtmektedir (Tablo 2). Hemşirelerin özellikle alt/pişik bakımı ve Abdel ve arkadaşları (2017) çalışmasına benzer şekilde termoregülasyonun düzenlenmesi uygulama kriterlerini bilme oranlarının düşük olduğu görülmüştür (23). Yenidoğan aile iletişimini sağlama kriterlerini bilme oranı termoregülasyonun düzenlenmesi ve alt/pişik bakımı kadar olmasa da düşüktür (Tablo 3). Hemşirelerin yaklaşık 1/3'ünün alt/pişik bakımında hekime bağımlı olduklarını düşünmeleri önemli bulunmuştur. Meslekte çalışma yılı yüksek olan hemşirelerin yenidoğanın alt/pişik bakımı konusunda daha az doğru yanıt vermiştir ve çalışma yılı ile istatistiksel olarak anlamlı bir ilişki vardır $(p<0,05)$.

\section{Kaynaklar}

1. Baykara ZG. Hemşirelik Bakımında Hemşirenin Mesleki Özerkliğinin Değerlendirilmesi, Niteliksel Bir Çalışma, Tıp Tarihi ve Etiği Anabilim Dalı, Doktora tezi, Ankara, Ankara Üniversitesi, 2010.

2. Welton JM, Zone-Smith L, Fischer MH. Adjustment of inpatient care reimbursement for nursing intensity. Policy Polit Nurs Pract 2006;7:270-80. [CrossRef]

3. Aştı $T$, Karadağ A. Hemşirelik esasları hemşirelik bilimi ve sanatı. İstanbul: Akademi Basın ve Yayıncılık; 2012. ss.226-7.

4. Taylan S, Alan S, Kadıoğlu S. Hemşirelik rolleri ve özerklik. Hemşirelikte Araştırma Geliştirme Derg 2012;3:66-74. http://hemarge.org.tr/ ckfinder/userfiles/files/10_makale_6.pdf

5. Yıldırım D. Hemşirelerin servislerde hastalarla ilgili ve diğer işlere ayırdıkları sürelerin belirlenmesi. İstanbul Üniversitesi Florence Nigthtingale Hemşirelik Yüksekokulu Derg 2006;14:177-92. https:// dergipark.org.tr/tr/download/article-file/95335

6. Avcı GG, Türker $S$, Çifçi $M$, Sürücü Ş. Yoğun bakım hemşirelerinin iş yükünün belirlenmesi. Yoğun Bakım Derg 2013;4:21-24.

7. Kaya H, Kaya N, Turan Y, Tan YM, Terzi B, Barlas DB. Nursing activities in intensive care units in Turkey. Int J Nurs Pract 2011;17:304-14. [CrossRef]

8. Baykara Z, Şahinoğlu S. Hemşirelikte mesleki özerklik kavramının incelenmesi. Anadolu Hemşirelik ve Sağlık Bilimleri Derg 2013;16:176-81.

9. Çavuşoğlu H. Çocuk Sağlığı Hemşireliği, 7. Baskı. Ankara: Sistem Ofset; 2004. s.23.

10. Hemşirelik Yönetmeliğinde Değişiklik Yapılmasına Dair Yönetmelik. T. C Resmi Gazete, Sayı:27910, 19 Nisan 2011. http:// www.turkhemsirelerdernegi.org.tr/tr/yasa-ve-yonetmelikler/ yonetmelikler/19-nisan-2011-hemsirelik-yonetmeligindedegisiklik-yapilmasina-dair-yonetmelik.aspx

11. Çökelek F. Yenidoğan Yoğun Bakım Ünitesinde Hemşirelik Bakımının Yoğunluğu, Gazi Üniversitesi Sağlık Bilimleri Enstitüsü, Yüksek Lisans Tezi, Ankara, Gazi Üniversitesi, 2012.

12. Tengir T, Çetinkaya Ş. Yenidoğan beslenmesinde kullanılan yöntemler ve hemşirelik bakımı. Fırat Sağlık Hizmetleri Derg 2008;3:119-40.

\section{Sonuç ve öneriler}

YYBÜ hemşirelerinin genel olarak uygulama rollerinin farkında olsa da rol karmaşası yaşadıkları ayrıca uygulamalara ait bakım verme kriterleri tam olarak bilmedikleri saptanmıştır. Literatürde yoğun bakım ünitelerinde hemşirelik bakım aktivitelerinin karşılaştırılması ile ilgili çalışma bulunmasına rağmen $(7,11,24)$ yoğun bakım ünitelerinde çalışan hemşirelerin diğer sağlık disiplinleri birlikte karar verip gerçekleştiren ve bağımsız olarak karar verilip gerçekleştirilen rollerinin bakım kriterlerine göre belirlenmesine yönelik herhangi bir çalışmaya rastlanmamıştır. $\mathrm{Bu}$ durum araştırma verilerinin karşılaştırılmasını zorlaştırmıştır. Hemşirelerin rol karmaşası yaşamalarının önüne geçilebilmesi için eğitim programları düzenlenmesi, hizmet içi eğitimler verilmesi ve görev, yetki, rollerini ve sorumluluklarını ortaya koyacak kurum politikalarının belirlenmesi, bakım kriterlerinin prosedürler doğrultusunda netleştirilmesi ve kurumsal prosedürleri geliştirilmesi, konu hakkında daha büyük gruplarla çalışmalar yapılması önerilebilir.

13. Selalmaz M, Bülbül A, Sözeri Ş, Özcan F, Kunt A, Atar G, et al Yenidoğan ünitelerinde çalışan hemşirelerin sarılık tedavisi konusunda uygulama düzeylerinin değerlendirilmesi. Şişli Etfal Eğitim Araştırma Hastanesi Tıp Bülteni 2015;49:195-9. [CrossRef]

14. Dursun $M$, Bülbül $A$. Mekanik ventilasyondaki yenidoğan bebeğin bakımı. Şişli Etfal Hastanesi Tıp Bülteni 2014;48:67-77. [CrossRef]

15. Sağlık Bakanlığı Sertifikalı Eğitim Yönetmeliği. Resmi Gazete, Sayı:27679, 21 Ağustos 2010. https://www.resmigazete.gov.tr/ eskiler/2010/08/20100821-2.htm

16. Gomes ACR, Silva CAG, Gamarra CJ, Fario JCO, Avelar AFM, Rodrigues EC. Assessment of phlebitis, infiltration and extravasation events in neonates submitted to intravenous therapy. Escola Anna Nery 2011;15:472-9. [CrossRef]

17. Blume-Peytavi U, Cork MJ, Faergemann J, Szczapa J, Vanaclocha F, Gelmetti C. Bathing and cleansing in newborns from day 1 to first year of life: recommendations from a European round table meeting. J Eur Acad Dermatol Venereol 2009;23:751-9. [CrossRef]

18. Akgün Kostak M, İnal S, Efe E, Bal Yılmaz H, Şenel Z. Determination of methods used by the neonatal care unit nurses for management of procedural pain in Turkey. J Pakistan Med Assoc 2015;65:526-31.

19. Johnston CC, Filion F, Campbell-Yeo M, Goulet C, Bell L, Mc Naughton $\mathrm{K}$, Byron J. Enhanced kangaroo mother-care for heel lance in preterm neonates: a crossover trial. Journal Perinatol 2009;29:51-6. [CrossRef]

20. Neal DO. Music as a health patterning modality for preterm infants in the nicu, in partial fulfillment of the requirements for the degree of doctor of philosophy. The Faculty of the Graduate School of the University of Minnesota; 2008.

21. Dimmit RA, Lawrance R. Clinical management of necrotizing enterocolitis. Am Acad Pediatr 2001;2:110-7.

22. Chandler JC, Hebra A. Necrotizing enterocolitis in infants with very low birth weight. Semin Pediatr Surg 2000;9:63-72. [CrossRef]

23. Abdel Rasoul GM, Zein El Dein NA, Khalaf SM, Ibrahim ASH. Effect of Designed Guidelines on Nurses' Performance to Prevent Preterm Infants' Hypothermia. Nurs Health Care Int J 2017;1:1-9. [CrossRef]

24. Çelik S, Karaman D, Yanık F, Veren F. Yoğun bakım hemşirelerinin kateter ile ilişkili üriner sistem enfeksiyonlarının önlenmesi hakkındaki bilgi durumları. Acıbadem Üniversitesi Sağlık Bilimleri Derg 2011;2:215-20. http://www.acibadem.dergisi.org/uploads/pdf/pdf_AUD_101.pdf 